\title{
Influência do tipo de dopante do substrato em células solares bifaciais finas
}

Graziella Fernandes Nassau Costa ${ }^{1}$ Adriano Moehlecke ${ }^{1 *}$ (1)

Izete Zanesco ${ }^{1}$

\section{Resumo}

A combinação do uso de células solares bifaciais e de lâminas finas de silício cristalino pode reduzir os custos de fabricação de módulos fotovoltaicos. O objetivo deste trabalho foi analisar a influência do tipo de dopante, $\mathrm{n}$ ou $\mathrm{p}$, de lâminas de silício monocristalino Czochralski, grau solar, nas características elétricas de células solares bifaciais finas com espessura da ordem de $140 \mu \mathrm{m}$. Foi desenvolvido o processo de fabricação das células solares, sendo que as etapas de texturação e metalização foram otimizadas. No que se refere ao processo de queima das pastas metálicas de $\mathrm{Ag}$ e Al, observou-se que a maior eficiência média dos dispositivos foi obtida com temperatura de $870{ }^{\circ} \mathrm{C}$. As células solares de maior eficiência foram as produzidas com as lâminas de Si tipo p, atingindo a eficiência de 13,9\% para iluminação pela face $\mathrm{n}^{+}$e 9,0\% para iluminação pela face $\mathrm{p}^{+}$, sem o uso de passivação de superfícies. Com as lâminas tipo n, as células solares bifaciais apresentaram maior simetria entre as eficiências sob os dois modos de iluminação, mas com valores da ordem de 1\%-2\% menores que as de silício tipo $\mathrm{p}$.

Palavras-chave: Células solares bifaciais; Lâminas de Si finas; Si tipo p e n.

\section{Influence of the substrate doping type on thin bifacial solar cells}

\begin{abstract}
The combination of the use of bifacial solar cells and thin crystalline silicon wafers can reduce the manufacturing costs of photovoltaic modules. The aim of this work was to analyze the influence of the doping type of Czochralski-grown monocrystalline silicon wafers, solar grade, n-type and p-type, on the electrical characteristics of $140 \mu \mathrm{m}$ thick bifacial solar cells. The solar cell manufacturing process was developed and the texture etch as well as the metal grid firing process were optimized. As regards the screen-printed Ag and Al metal grid firing, it was observed that the higher average efficiency of the devices was obtained with a temperature of $870{ }^{\circ} \mathrm{C}$. The most efficient solar cells were manufactured with p-type wafer, reaching $13.9 \%$ when the device was illuminated by $\mathrm{n}^{+}$face and $9.0 \%$ when was illuminated $\mathrm{p}^{+}$face, without any surface passivation. By using n-type wafers, bifacial solar cells presented higher simmetry between front and rear side illumination mode, but with values on the order of $1 \%-2 \%$ lower than p-type Si devices.
\end{abstract}

Keywords: Bifacial solar cells; Thin Si wafers; N-type and p-type silicon.

\section{Introdução}

As células solares industriais são produzidas usando lâminas de silício cristalino com $180 \mu \mathrm{m}$ de espessura, multicristalinas ou monocristalinas obtidas pelo método Czochralski (Cz). A maioria das lâminas usadas são tipo $\mathrm{p}$, dopadas com boro e a estrutura $\mathrm{n}^{+} \mathrm{pp}^{+}$é um padrão nas indústrias de células solares com emissor $\mathrm{n}^{+}$formado por difusão de fósforo e região $\mathrm{p}^{+}$, de campo retrodifusor (BSF, back surface field), formado por pasta de alumínio depositada por serigrafia e difusão em forno de esteira [1]. Como o alumínio recobre toda a face posterior, estas estruturas somente podem ser usadas como células solares monofaciais.

Segundo o International Technology Road Map for Photovoltaics, ITRPV, de 2019 [2], o uso do silício monocristalino tipo n pela indústria de células solares crescerá dos atuais $5 \%$ para aproximadamente $40 \%$ da produção em 2029. As vantagens dos substratos tipo $n$ frente aos tipo $p$ referem-se a ausência de centros de recombinação causados pela interação da radiação solar com os pares boro-oxigênio presentes nos substratos dopados tipo p [3] e

${ }^{l}$ Escola Politécnica, Pontificia Universidade Católica do Rio Grande do Sul-PUCRS, Porto Alegre, RS, Brasil.

*Autor correspondente: moehleck@pucrs.br

2176-1523 C 2021. Costa et al. Publicado pela ABM. Este é um artigo publicado em acesso aberto (Open Access) sob a licença Creative Commons Attribution, que permite uso, distribuição e reprodução em qualquer meio, sem restrições desde que o trabalho original seja corretamente citado. 
a menor influência de contaminantes metálicos na eficiência das células solares [4]. Contaminantes como Fe intersticial capturam de forma eficaz os elétrons e, como no caso de lâminas de Si tipo n os portadores minoritários são as lacunas, estes contaminantes são menos eficientes no processo de recombinação, resultando em maiores tempos de vida dos portadores minoritários. Outra tendência apresentada no ITRPV é a redução da espessura das lâminas de silício, que será reduzida dos atuais $180 \mu \mathrm{m}$ para $130 \mu \mathrm{m}$ com o objetivo de diminuir custos de produção, pois atualmente a lâmina representa da ordem de $52 \%$ dos custos de uma célula solar. Para esta última espessura, o alumínio depositado em forma de pasta de serigrafia não poderá ser utilizado como dopante tendo em vista os problemas de abaulamento das lâminas de silício [5].

As células solares bifaciais, isto é, ativas em ambas faces, representam uma forma para reduzir os custos da energia elétrica obtida de sistemas fotovoltaicos ao aproveitar a radiação solar refletida pelas superfícies do local onde os módulos fotovoltaicos são instalados ou pelo uso de concentradores de radiação solar [6-8]. Células solares do tipo $\mathrm{n}^{+} \mathrm{pp}^{+} \mathrm{e} \mathrm{p}^{+} \mathrm{nn}^{+}$, com região $\mathrm{n}^{+}$dopada com fósforo e $\mathrm{p}^{+}$dopada com boro podem ser bifaciais, isto é, projetadas para receber radiação solar nas duas faces [6]. Para a iluminação pelas faces sem a junção pn, isto é, face $\mathrm{n}^{+} \mathrm{n}$ ou $\mathrm{p}^{+} \mathrm{p}$, dependendo do tipo de dopagem do substrato, os portadores de carga minoritários produzidos pelos fótons absorvidos devem percorrer toda a espessura da lâmina para serem coletados pela junção pn e contribuírem para a corrente e tensão elétrica do dispositivo. Por esta razão, as lâminas de menor espessura, além de reduzir os custos de produção, podem incrementar a eficiência dos dispositivos quando a iluminação for pela face sem a junção pn. Moehlecke et al. [9] compararam dispositivos com diferentes dopagens de substrato e concluíram que a estrutura $\mathrm{p}^{+} \mathrm{nn}^{+}$seria a mais adequada para células solares bifaciais porque para iluminação pela face $\mathrm{p}^{+}$, quando há junção pn, a corrente elétrica produzida é maior. Por outro lado, observaram que a estrutura $\mathrm{n}^{+} \mathrm{pp}^{+}$é mais adequada quando os substratos tinham baixo tempo de vida dos portadores minoritários porque a mobilidade dos elétrons é maior que a de lacunas e desta forma, tem maior comprimento de difusão.

$\mathrm{O}$ desenvolvimento de células solares em lâminas finas é realizado com lâminas de espessura convencional e que passam por processos de afinamento com soluções ácidas ou básicas, pois ainda não se encontram no mercado lâminas finas de silício. Por exemplo, Pan et al. [10] produziram células solares bifaciais de $4 \mathrm{~cm}^{2}$ com substratos $\mathrm{Si}-\mathrm{Cz}$ dos tipos $\mathrm{p}$ e n, espessuras de $140 \mu \mathrm{m}$ (obtida de lâminas de $240 \mu \mathrm{m}$ afinadas) e $240 \mu \mathrm{m}$. As estruturas usadas foram $\mathrm{p}^{+} \mathrm{nn}^{+} \mathrm{en}^{+} \mathrm{pp}^{+}$ com emissores implementados com difusão de boro e fósforo com as fontes líquidas, $\mathrm{BBr}_{3}$ e $\mathrm{POCl}_{3}$, respectivamente.

Os autores concluíram que as maiores eficiências foram apresentadas para dispositivos em substrato tipo $\mathrm{n}$ e quando os mesmos foram iluminados pela região de $\mathrm{BSF} \mathrm{n}^{+} \mathrm{n}$, pois foi observada uma menor recombinação de portadores de carga minoritários na superfície $\mathrm{n}^{+}$bem como na base do dispositivo. Com a estrutura $\mathrm{n}^{+} \mathrm{p}$ e a superfície frontal e posterior passivada com SiNx e região de BSF de Al localizada somente no contato elétrico da face posterior, foram obtidas as eficiências de 14,6\%/13,6\% (frontal/posterior) em dispositivos de área reduzida $\left(4 \mathrm{~cm}^{2}\right)$ e com lâminas de silício $\mathrm{Cz}$ de $140 \mu \mathrm{m}$ de espessura [11]. A partir de lâminas de $\mathrm{Si}-\mathrm{Cz}$, tipo p, de $550 \mu \mathrm{m}$ de espessura, Osório et al. [12,13] desenvolveram um processo para fabricação de células solares bifaciais $\mathrm{n}^{+} \mathrm{pp}^{+}$com espessura média de 145-150 $\mu \mathrm{m}$. O processo de afinamento tinha como base um ataque químico do silício composto por hidróxido de potássio e água deionizada [12]. Foram fabricados dispositivos bifaciais de $61,58 \mathrm{~cm}^{2} \mathrm{com}$ eficiências de $14,0 \%$ e de $10,4 \%$ para iluminação pela face $n^{+}$ $\mathrm{e}^{+}$, respectivamente [13]. Nestas células solares, a região $\mathrm{n}^{+}$ foi obtida mediante difusão de fósforo usando $\mathrm{POCl}_{3}$ como fonte. A região $\mathrm{p}^{+}$foi produzida pela deposição de boro por spin-on e difusão em forno de tubo de quartzo bem como pela deposição de pasta de alumínio por serigrafia e difusão em forno de esteira. As superfícies não foram recobertas com filmes passivadores. Com lâminas de $\mathrm{Si}-\mathrm{Cz}$, tipo n, Moehlecke et al. [14] e Campos et al. [15] reportaram resultados de células solares fabricadas em lâminas de $135-140 \mu \mathrm{m}$ de espessura. Comparando as estruturas $\mathrm{n}^{+} \mathrm{np}^{+} \mathrm{e}$ $\mathrm{p}^{+} \mathrm{nn}^{+}$para aplicação em módulos fotovoltaicos monofaciais, concluiu-se que a primeira estrutura era a mais adequada para produção de células solares finas em lâminas de silício n, atingindo a efíciência de 13,8\% sem o uso de passivação de superfícies [15].

O objetivo deste trabalho é apresentar a análise da influência do tipo de dopante, $\mathrm{n}$ e p, de lâminas de silício monocristalino Czochralski, grau solar, nas características elétricas de células solares bifaciais finas com espessura da ordem de $140 \mu \mathrm{m}$. As lâminas de silício finas foram obtidas a partir do lingote, por corte com fios, em processo experimental de fabricação deste tipo de lâmina e foram fornecidas pela empresa Meyer-Burger, da Suíça. Desta maneira, pela primeira vez se fabricaram células solares sobre lâminas finas originadas no processo de corte do lingote. Foram fabricadas células solares e comparadas suas características elétricas.

\section{Materiais e métodos}

$\mathrm{Na}$ Tabela 1 apresenta-se a sequência das etapas utilizadas para produzir as células solares em lâminas finas [14,15]. O processo é composto de etapas texturação das superfícies para reduzir a refletância, limpeza RCA para redução de contaminantes na superfície das lâminas de silício [16], deposição de boro por spin-on (usando o polyboron PBF20 da Filmtronics, EUA) e evaporação dos solventes, difusão de boro a $975{ }^{\circ} \mathrm{C}$ e oxidação a $1000{ }^{\circ} \mathrm{C}[17,18]$, deposição de resina na face com boro e ataque de óxidos com solução de $\mathrm{HF}$ tamponado $\left(\mathrm{HF}+\mathrm{NH}_{4} \mathrm{~F}\right)$, limpeza da resina com acetona+álcool isopropílico $+\mathrm{H}_{2} \mathrm{O}_{\mathrm{DI}}$, limpeza RCA, difusão de fósforo na temperatura de $855^{\circ} \mathrm{C}$ [19] e usando 
Tabela 1. Etapas do processo utilizado para produzir as células solares bifaciais

\begin{tabular}{cl}
\hline Etapa & \multicolumn{1}{c}{ Descrição da Etapa } \\
\hline 1 & Texturação \\
2 & Limpeza RCA \\
3 & Deposição de boro por spin-on e evaporação dos solventes \\
4 & Difusão de boro para formar a região $\mathrm{p}^{+}$e oxidação \\
5 & Deposição de resina na face com boro e extração do $\mathrm{SiO}_{2}$ \\
& da outra face \\
6 & Remoção da resina e limpeza $\mathrm{RCA}$ \\
7 & Difusão de fósforo a partir de $\mathrm{POCl}_{3}$ para formar a região $\mathrm{n}^{+}$ \\
8 & Ataque dos silicatos de $\mathrm{P}$ e $\mathrm{B}$ e limpeza $\mathrm{RCA}$ \\
9 & Deposição de filme antirreflexo de $\mathrm{TiO}_{2}$ na face $\mathrm{n}^{+}(80 \mathrm{~nm})$ \\
10 & Deposição da malha metálica de $\mathrm{Ag}\left(\right.$ face $\left.^{+}\right)$e $\mathrm{Ag} / \mathrm{Al}\left(\right.$ face $\left.\mathrm{p}^{+}\right)$ \\
11 & Queima das pastas metálicas \\
12 & Deposição de filme antirreflexo de $\mathrm{TiO}_{2}$ na face $\mathrm{p}^{+}(70 \mathrm{~nm})$ \\
13 & Isolamento de bordas com feixe laser \\
\hline
\end{tabular}

o $\mathrm{POCl}_{3}$ como fonte de fósforo, ataque dos silicatos de boro e fósforo em solução com HF, limpeza RCA, deposição de filme antirreflexo (AR) de $\mathrm{TiO}_{2}$ por evaporação em alto vácuo, metalização das faces frontal e posterior com pastas metálicas e queima das mesmas em forno de esteira e isolamento de bordas.

As lâminas de silício fornecidas pela empresa MeyerBurger, da Suíça, eram pseudo-quadradas, com $125 \mathrm{~mm} x$ $125 \mathrm{~mm}$, com orientação dos planos cristalográficos $\{100\}$. A espessura e a resistividade das lâminas de silício foram medidas após o processo de texturação, que consta de um ataque anisotrópico das superfícies para retirar os primeiros micrômetros danificados pelo processo de corte e para texturar as superfícies, isto é, criar micropirâmides para reduzir a reflexão da radiação solar. Foram caracterizadas quatro lâminas de cada tipo de dopagem, $\mathrm{n}$ e p. A espessura foi medida em quatro pontos com um micrômetro digital e a resistividade foi calculada a partir da medida da resistência de folha usando a técnica de "quatro pontas" [20]. As amostras apresentaram os seguintes valores médios de espessura e resistividade: a) tipo $\mathrm{n}, 139 \mu \mathrm{m}$ e $1,9 \Omega . \mathrm{cm}$ e b) tipo $\mathrm{p}$, $149 \mu \mathrm{m}$ e 2,0 $\Omega . \mathrm{cm}$.

Para a texturação, usou-se a solução padrão do NT-Solar/PUCRS [17] e foram empregados dois tempos de imersão em solução de $\mathrm{KOH}$, de 50 min e $60 \mathrm{~min}$, conforme resultados anteriores obtidos por Campos et al. [15]. A refletância média ponderada $\left(\rho_{\mathrm{w}}\right)$, refletância que considera o espectro solar e a resposta espectral de células solares de silício, foi usada como parâmetro para otimização do processo [21]. Foram utilizadas duas lâminas de Si tipo $\mathrm{n}$ e duas de tipo $\mathrm{p}$ e mediu-se a refletância hemisférica espectral em cinco pontos distintos de cada face. A partir destas medidas, calculou-se a refletância média ponderada para cada ponto e depois se determinou o valor médio e o desvio padrão deste parâmetro para cada tempo de ataque químico de texturação. Usou-se a microscopia eletrônica de varredura para a medição das alturas das pirâmides obtidas no processo de texturação. Alturas maiores que $10 \mu \mathrm{m}$ podem produzir baixas refletâncias, mas inviabilizam a formação de malhas metálicas pelo processo de serigrafia.

Em relação à difusão de fósforo e de boro, nos três lotes processados, a resistência de folha, medida pela técnica de "quatro pontas", da região $\mathrm{n}^{+}$nas lâminas tipo p, manteve-se da ordem de $45 \Omega / \square$, mas a região $\mathrm{p}^{+}$variou de $30 \Omega / \square$ a $40 \Omega / \square$. Nos substratos tipo n, a resistência de folha na região $\mathrm{n}^{+}$foi de aproximadamente $50 \Omega / \square$ e na região $\mathrm{p}^{+}$foi de $45 \Omega / \square$.

A metalização das faces frontal e posterior foi realizada pela deposição por serigrafia de uma malha de prata (na face $\mathrm{n}^{+}$) com a pasta PV17A da Dupont e de alumínio (na face $\mathrm{p}^{+}$) com a pasta PV381 (Dupont). Depois da deposição, as pastas de $\mathrm{Al}$ e Ag foram secadas em forno de esteira e em seguida, as lâminas foram submetidas a um processo térmico de alta temperatura em forno de esteira para estabelecer o contato elétrico com a lâmina de silício.

O processo de queima de pastas de serigrafia foi otimizado considerando a eficiência das células solares e a temperatura de queima $\left(\mathrm{T}_{\text {Queima }}\right)$ em forno de esteira. Foram produzidas células solares com temperaturas de queima de $850{ }^{\circ} \mathrm{C}$ a $890{ }^{\circ} \mathrm{C}$, em intervalos de $10^{\circ} \mathrm{C}$. Esta faixa de temperaturas foi previamente estabelecida com dispositivos finos fabricados em lâminas tipo $\mathrm{n}$ [15].

A deposição de $\mathrm{TiO}_{2}$ na face $\mathrm{n}^{+}$foi realizada antes da metalização, mas na face $\mathrm{p}^{+}$foi realizada depois desta etapa porque a pasta PV381 não perfura de forma eficaz o filme AR [14]. Na face com fósforo $\left(\mathrm{n}^{+}\right)$depositou-se um filme AR de $80 \mathrm{~nm}$ e na face com boro $\left(\mathrm{p}^{+}\right)$um filme de $70 \mathrm{~nm}$ de espessura [22]. A diferença deve-se ao fato que o filme de $80 \mathrm{~nm}$ passa pelo processo térmico de queima das pastas de serigrafia, que diminui sua espessura. Na última etapa do processo, denominado de isolamento das bordas, as células solares foram cortadas por meio de um sistema com radiação laser para obter dispositivos pseudo-quadrados de $80 \mathrm{~mm}$ x $80 \mathrm{~mm}$, com área de $61,58 \mathrm{~cm}^{2}$.

As células solares foram caracterizadas sob condições padrão $\left(100 \mathrm{~mW} / \mathrm{cm}^{2}\right.$, espectro $\left.\mathrm{AM} 1,5 \mathrm{G} \mathrm{e} 25^{\circ} \mathrm{C}\right) \mathrm{em}$ um simulador solar classe AAA, iluminando-as pelas faces $\mathrm{n}^{+} \mathrm{e}$ $\mathrm{p}^{+}$, independentemente. A partir da curva característica J-V (densidade de corrente elétrica-tensão elétrica), foram obtidos os parâmetros elétricos dos dispositivos: 1) densidade de corrente de curto-circuito $\left.\left(\mathrm{J}_{\mathrm{SC}}\right) ; 2\right)$ tensão de circuito aberto $\left.\left(\mathrm{V}_{\mathrm{OC}}\right) ; 3\right)$ fator de forma $(\mathrm{FF})$ e eficiência $(\eta)$. Foi medida a resposta espectral e refletância espectral e calculada a eficiência quântica interna (EQI) dos dispositivos de maior eficiência.

\section{Resultados e discussão}

\subsection{Análise do processo de texturação das superfícies}

A Figura 1 apresenta a imagem de microscopia eletrônica de varredura da superfície da lâmina de silício e 


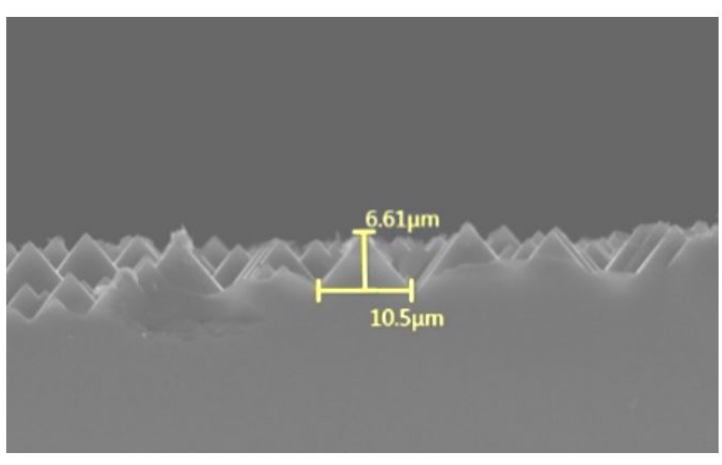

(a)

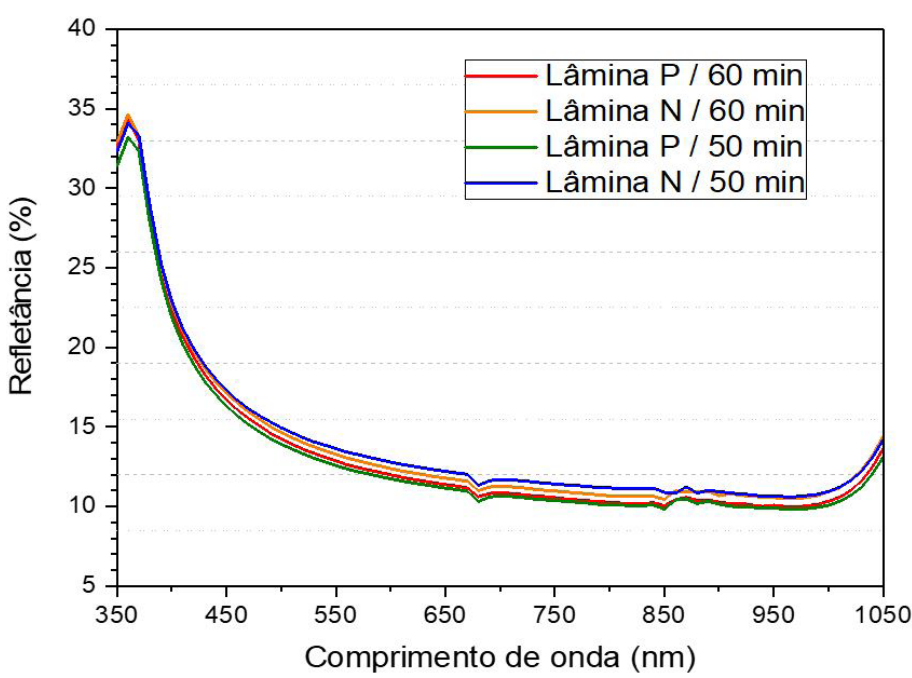

(b)

Figura 1. (a) Imagem de MEV da lâmina P50 (tipo p, texturação em 50 min); (b) Refletância de lâminas finas texturadas, com diferentes tempos de processo de ataque anisotrópico. As refletâncias hemisféricas correspondem ao ponto central de uma amostra circular de $100 \mathrm{~mm}$ diâmetro.

a refletância hemisférica espectral na região central de uma lâmina de silício após o processo de texturação. A altura das micropirâmides ficou entre $5,8 \mu \mathrm{m}$ e $9,7 \mu \mathrm{m}$ e na Figura 1a é mostrado o perfil destas micropirâmides em uma lâmina tipo $\mathrm{n}$ que passou pelo processo de texturação por $50 \mathrm{~min}$.

Da Figura 1b, observa-se que a refletância hemisférica atinge os menores valores para a lâmina de Si tipo $\mathrm{p}$ com o processo de texturação realizado durante $50 \mathrm{~min}$. A Tabela 2 resume os valores médios da refletância média ponderada determinada para as diferentes regiões das amostras. As lâminas de Si tipo $\mathrm{p}$ apresentaram os menores valores médios de $\rho_{\mathrm{w}}$, mas isto não se explica pela diferença de tipo de dopante, pois superfícies dopadas com boro são mais difíceis de serem texturadas [23]. O menor valor ficou próximo do obtido por Campos et al. [15], que obteve 11,3\% para lâminas tipo n afinadas quimicamente e dos resultados apresentados por Papet et al. [24], que alcançaram refletâncias de 12\%.

Considerando a menor $\rho_{\mathrm{w}}$ das lâminas de Si tipo $\mathrm{p}$ para o tempo de processamento de $50 \mathrm{~min}$ e que as de tipo n não mostraram redução de refletância para o tempo de $60 \mathrm{~min}$, selecionou-se o tempo de $50 \mathrm{~min}$ para a texturação.

\subsection{Otimização do processo de queima de pastas de serigrafia}

Células solares bifaciais foram processadas com temperatura de queima das pastas de $\mathrm{Ag}$ e de $\mathrm{Al}$ de $850^{\circ} \mathrm{C}$ a $890^{\circ} \mathrm{C}$. A Figura 2 apresenta a eficiência média de conversão de energia de células solares fabricadas em lâminas tipo $\mathrm{n}$ e p, para os dois modos de iluminação, isto é, pela face $\mathrm{n}^{+}$ ou $\mathrm{p}^{+}$, independentemente. Também se mostra a eficiência máxima $\left(\eta_{\text {Máx }}\right)$ obtida para cada tipo de célula solar e modo de iluminação.

Pela análise dos valores médios de eficiência, nota-se que tanto as células solares com substrato tipo $\mathrm{n}$
Tabela 2. Valor médio da $\rho_{w}$ para cada tempo de texturação e tipo de lâmina de silício

\begin{tabular}{ccc}
\hline \multirow{2}{*}{ Lâmina/tempo (min) } & \multicolumn{2}{c}{$\boldsymbol{\rho}_{\mathbf{w}}$ média (\%) } \\
\cline { 2 - 3 } & $\mathbf{5 0}$ & $\mathbf{6 0}$ \\
\hline Tipo P & $11,85 \pm 0,08$ & $12,4 \pm 0,3$ \\
Tipo N & $13,0 \pm 0,2$ & $12,98 \pm 0,09$ \\
\hline
\end{tabular}

quanto tipo $\mathrm{p}$, quando iluminadas pela face $\mathrm{n}^{+}$, dopada com fósforo, apresentaram as maiores eficiências para a $\mathrm{T}_{\text {Oueima }}$ de $870{ }^{\circ} \mathrm{C}$. As eficiências máximas também foram obtidas com $\mathrm{T}_{\text {Queima }}=870^{\circ} \mathrm{C}$. Para este modo de iluminação, a eficiência média das células solares em substratos $p$ atingiu valores da ordem de $13,3 \%$ e em substrato $n$ atingiu $12,4 \%$.

Cabe comentar que nos dispositivos com lâminas tipo $\mathrm{n}$, as eficiências para os dois modos de iluminação foram similares, sendo que a diferença é da ordem de 1\% (absoluto). Para o caso das células solares $\mathrm{n}^{+} \mathrm{pp}^{+}$, a diferença entre as eficiências para cada modo de iluminação foi maior, chegando a 4\% (absolutos). Atribui-se esta diferença de eficiências entre os dois modos de iluminação a maior recombinação de portadores de carga minoritários na face $\mathrm{p}^{+}$, que reduz a eficiência das células solares iluminadas pela região $\mathrm{p}^{+} \mathrm{p}$ de forma mais eficaz que das regiões $\mathrm{p}^{+} \mathrm{n}$.

\subsection{Características elétricas das células solares com maior eficiência}

As características J-V das células solares de maior eficiência em substratos de $\mathrm{Si}-\mathrm{Cz}$ tipo p e tipo $n$ são ilustradas na Figura 3. Para determinar a célula solar bifacial mais eficiente, considerou-se a aplicação da célula solar em módulos fotovoltaicos que utilizam a radiação de albedo ou de estruturas com refletores difusos [8,25]. Tomou-se como face frontal aquela com maior eficiência (ou maior 


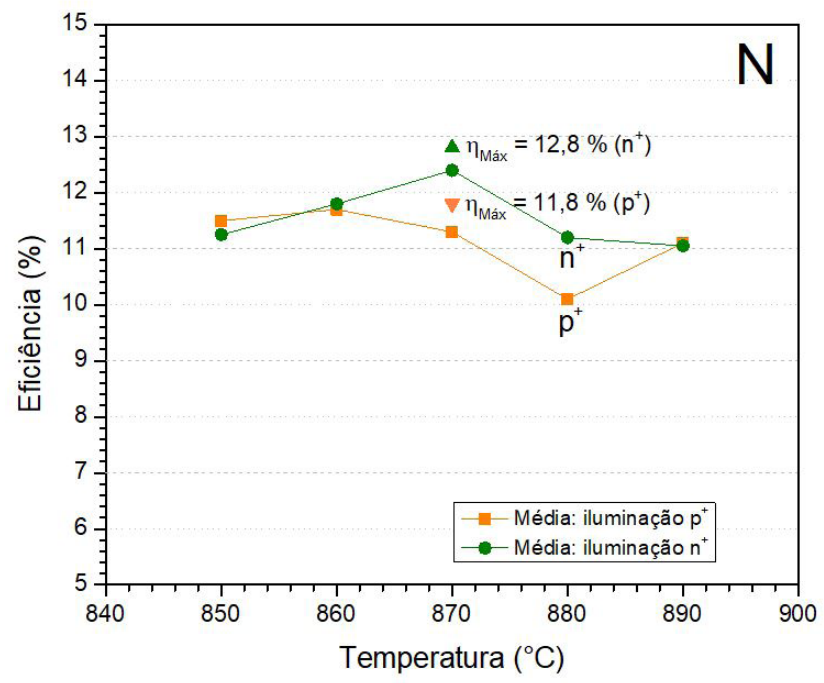

(a)

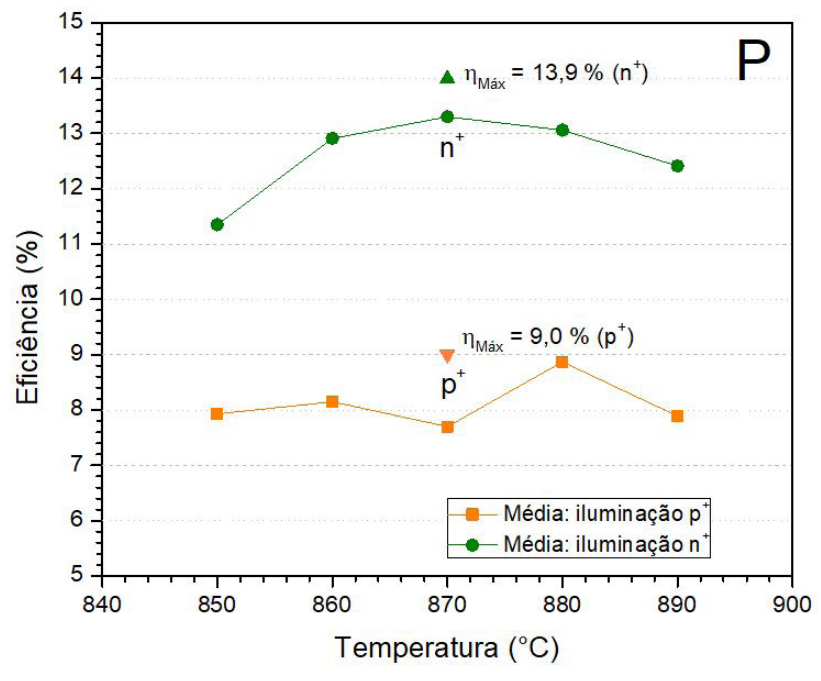

(b)

Figura 2. Eficiência média das células solares bifaciais processadas com substrato (a) tipo $\mathrm{N}$ e (b) tipo $\mathrm{P}$ em função da temperatura de queima das pastas de metalização. Os valores máximos de eficiência $\left(\eta_{\text {Máx }}\right)$ para $\mathrm{T}_{\text {Queima }}=870^{\circ} \mathrm{C}$ também estão indicados.

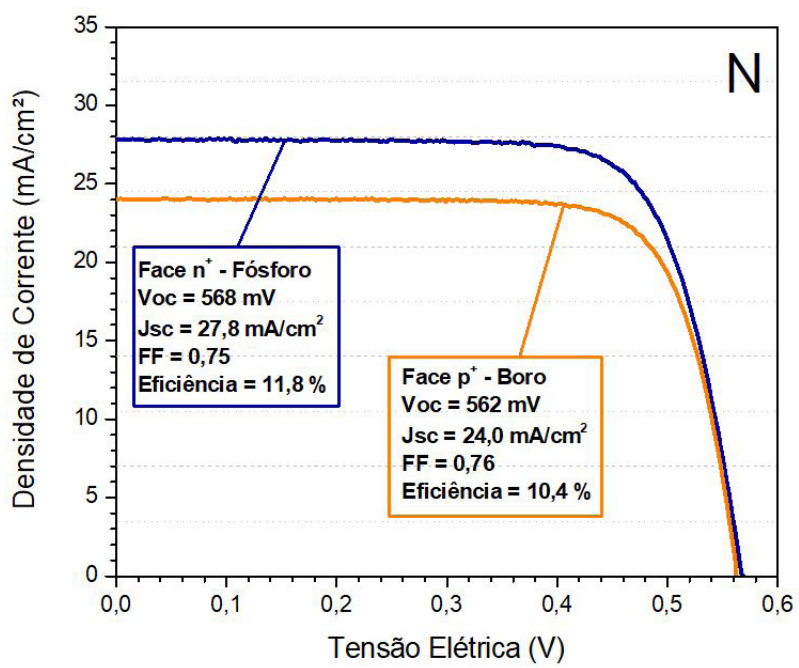

(a)

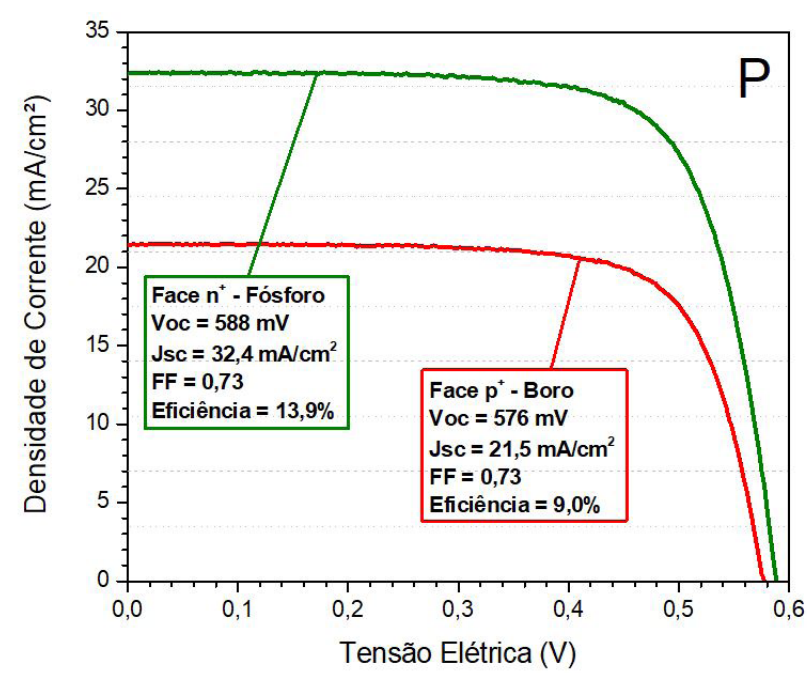

(b)

Figura 3. Curvas características J-V de células solares bifaciais de maior eficiência em (a) substrato $\mathrm{N}$ e (b) substrato $\mathrm{P}$.

potência). Portanto, considerou-se a potência da célula iluminada pela face $\mathrm{n}^{+}$como frontal e somaram-se $25 \%$ da potência quando a célula solar foi iluminada pela face $\mathrm{p}^{+}$ ou posterior. A célula solar que apresentou a maior potência total nesta situação foi selecionada para a análise.

Observa-se que o dispositivo processado em lâminas de Si tipo $\mathrm{p}$ atingiu maior valor de $\mathrm{J}_{\mathrm{SC}}, \mathrm{V}_{\mathrm{OC}}$ e $\eta$. Atribui-se estes maiores valores a uma maior qualidade do substrato tipo $\mathrm{p}$ fornecido pela empresa Meyer-Burger, com maior comprimento de difusão dos portadores minoritários.

Ao comparar os resultados de células base p obtidos neste trabalho com os publicados por Osório et al. [12], que usou lâminas de silício tipo $\mathrm{p}$ afinadas quimicamente e com resistividade de 1-20 $\Omega . \mathrm{cm}$, constata-se que as eficiências são iguais para iluminação pela face $\mathrm{n}^{+}$. No entanto, $a V_{O C}$ apresentada por Osório et al. [12] foi da ordem de $10 \mathrm{mV}$ superior, o que se atribui a uma maior qualidade da lâmina de silício.

As células solares base $\mathrm{n}$ produzidas apresentaram eficiências inferiores às obtidas com dispositivos base $\mathrm{n}$ e lâminas de outro fornecedor [15], sendo de $1 \%$ a $2 \%$ menores para iluminação pela face $\mathrm{n}^{+} \mathrm{e}^{+}$, respectivamente. A tensão de circuito aberto medida nos dispositivos fabricados com lâminas $n$ afinadas [15] foi da ordem 


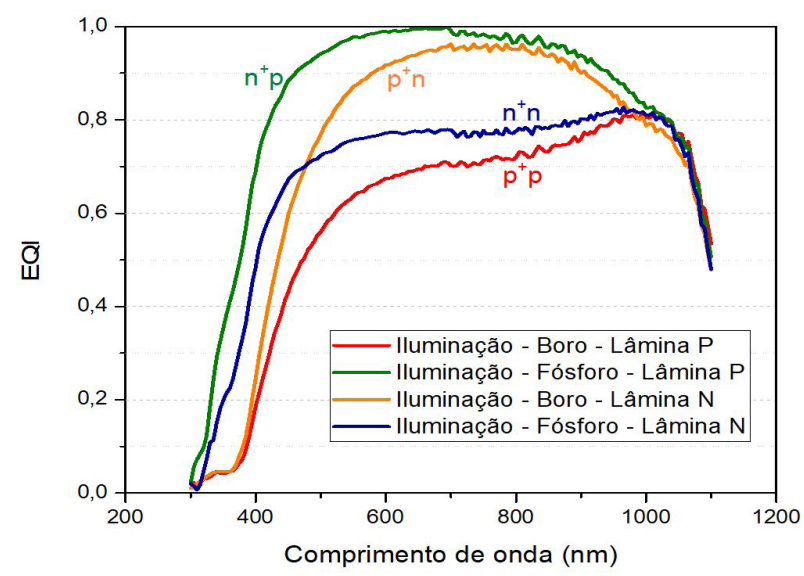

Figura 4. Eficiência quântica interna das células solares bifaciais de maior eficiência processadas em substrato de Si tipo p e tipo n.

de 13-16 mV acima dos valores apresentados neste trabalho. Cabe comentar que as lâminas de Si usadas por Campos et al. [15] tinham resistividade de 1-20 $\Omega . c m$ e as de tipo $\mathrm{n}$ deste trabalho tem da ordem de $1,9 \Omega \mathrm{cm}$. Esta diferença em resistividade não explica os menores valores de $\eta \mathrm{e} \mathrm{V}_{\mathrm{OC}}$ observados, sendo que as lâminas de Si usadas por Campos et al [15] devem ter um tempo de vida dos portadores de carga minoritários maior que as usadas neste trabalho.

A Figura 4 apresenta a eficiência quântica interna dos dispositivos fabricados em lâminas de Si tipo $\mathrm{p}$ e n. A menor EQI das células solares iluminadas pela face $\mathrm{p}^{+}$, na faixa de menores comprimentos de onda, isto é, de $300 \mathrm{~nm}$ a $600 \mathrm{~nm}$, indica uma alta recombinação em superfície que reduz a $\mathrm{J}_{\mathrm{SC}}$ e a eficiência das células solares.

\section{Conclusões}

Neste trabalho foi analisada a influência do tipo de dopagem do substrato, tipo $\mathrm{n}$ e tipo $\mathrm{p}$, nas características elétricas de células solares bifaciais com lâminas finas obtidas diretamente com corte do lingote por fios.

O processo de fabricação de células solares utilizado foi desenvolvido em trabalhos anteriores [14,15,17,19] e duas etapas foram otimizadas: a texturação e a metalização. Para a primeira, verificou-se que são necessários 50 min de texturação na solução padrão do NT-Solar para produzir uma $\rho_{\mathrm{w}}$ da ordem de $12 \%$. Constatou-se que a temperatura de queima simultânea das pastas de $\mathrm{Ag}$ e Al, depositadas sobre a face $\mathrm{n}^{+} \mathrm{e}^{+}$, respectivamente, deve ser de $870{ }^{\circ} \mathrm{C}$.

Pelos resultados obtidos, tanto as células solares base $\mathrm{n}$ quanto as base $\mathrm{p}$, quando iluminadas pela face $\mathrm{n}^{+}$, dopada com fósforo, apresentaram as maiores eficiências, atingindo valores da ordem de $13,9 \%$ (substrato tipo $p$ ) e de 12,8\% (tipo n), sem passivação das superfícies. Ao comparar estes resultados com os de células solares obtidas por processos similares e processadas com lâminas de outros fabricantes e quimicamente afinadas, a estrutura $\mathrm{n}^{+} \mathrm{np}^{+}$apresentou eficiência $1 \%$ menor, indicando que os substratos utilizados têm um menor tempo de vida dos portadores minoritários.

Quanto ao tipo de dopagem do substrato, e considerando as lâminas de Si produzidas experimentalmente, pôde-se concluir que as células solares fabricadas com o substrato tipo $\mathrm{n}$ e sem superfícies passivadas apresentaram maior simetria entre a eficiências com os dois modos de iluminação. Mas a maior eficiência frontal da estrutura $\mathrm{n}^{+} \mathrm{pp}^{+}$desenvolvida indica esta estrutura como a mais conveniente para uso como célula bifacial.

\section{Agradecimentos}

O trabalho foi realizado no âmbito do projeto "Células Solares Bifaciais em Substratos Finos e com Região $\mathrm{p}^{+}$ Localizada", Contrato PUCRS-CEEE nº. 9942397. Os autores agradecem a empresa Meyer Burguer Technology S.A, da Suiça, pelo fornecimento das lâminas finas de silício monocristalino. Também agradecem o apoio do CNPq e da CAPES, pelas bolsas concedidas, e à equipe do NT-Solar/ PUCRS pelo apoio na fabricação das células solares.

\section{Referências}

1 Battaglia C, Cuevas A, De Wolf S. High-efficiency crystalline silicon solar cells: status and perspectives. Energy \& Environmental Science. 2016;9(5):1552-1576.

2 International Technology Roadmap for Photovoltaic. ITRPV 2018 results. 10th ed. 2019 [acesso em 4 jul. 2019]. Disponível em: http://itrpv.vdma.org

3 Sopori B, Basnyat P, Devayajanam S, Shet S, Mehta V, Binns J, et al. Understanding light-induced degradation of c-Si solar cells. In: Proceedings of the $38^{\text {th }}$ IEEE Photovoltaic Specialists Conference; 2012; Austin, Texas. New York: IEEE; 2012. p. 1115-1120. http://dx.doi.org/10.1109/PVSC.2012.6317798.

4 Rehman A, Lee SH. Advancements in n-type base crystalline silicon solar cells and their emergence in the photovoltaic industry. The Scientific World Journal. 2013;2013:470347. http://dx.doi.org/10.1155/2013/470347.

5 Lim JR, Kim S, Ahn HK, Song HE, Kang GH. Analysis of the bowing phenomenon for thin c-Si solar cells using partially processed c-Si solar cells. Energies. 2019;12(9):1593. http://dx.doi.org/10.3390/en12091593. 
6 Guerrero-Lemus R, Vega R, Kim T, Kimm A, Shephard LE. Bifacial solar photovoltaics: a technology review. Renewable \& Sustainable Energy Reviews. 2016;60:1533-1549.

7 Zanesco I, Lorenzo E. Optimisation of an asymmetric static concentrator: the PEC-44D. Progress in Photovoltaics: Research and Applications. 2002;10(5):361-376.

8 Moehlecke A, Febras FS, Zanesco I. Electrical performance analysis of PV modules with bifacial silicon solar cells and white diffuse reflector. Solar Energy. 2013;96:253-262.

9 Moehlecke A, Zanesco I, Canizo C, Luque A. Experimental comparison between $\mathrm{p}$ and $\mathrm{n}$ bases for bifacial solar cells. In: Proceedings of the $13^{\text {th }}$ European Photovoltaic Solar Energy Conference and Exhibition; 1995; Nice, França. Munique: WIP; 1995. p. 1242-1245.

10 Pan AC, del Cañizo C, Luque A. Effect of thickness on bifacial silicon solar cells. In: 2007 Spanish Conference on Electron Devices; 2007; Madrid, Spain. New York: IEEE; 2007, p. 234-237. http://dx.doi.org/10.1109/ SCED.2007.384035.

11 Steckemetz S, Metz A, Hezel R. Thin Cz-silicon solar cells with rear silicon nitride passivation and screen printed contacts. In: Proceedings of the $17^{\text {th }}$ European Photovoltaic Solar Energy Conference and Exhibition; 2001; Munique. Alemanha: WIP; 2001. p. 1902-1906.

12 Osório VC, Moehlecke A, Zanesco I. Influence of the order of boron and phosphorus diffusion on the fabrication of thin bifacial silicon solar cells. Materials Research Express. 2016;3:1-7.

13 Osório VC, Moehlecke A, Zanesco I. Células solares bifaciais industriais em lâminas de silício finas: análise de passivação de superfícies e tipo de silício. Cerâmica. 2018;64(370):183-189. http://dx.doi.org/10.1590/036669132018643702280.

14 Moehlecke A, Campos RC, Zanesco I. Células solares finas em silício tipo n: avaliação de diferentes pastas metálicas para contato elétrico da face dopada com boro. Tecnologica em Metalurgia, Materiais e Mineração. 2017;14(3):250-256.

15 Campos RC, Moehlecke A, Zanesco I, Ly M. Desenvolvimento e comparação de células solares com estruturas $\mathrm{p}^{+} \mathrm{nn}^{+}$e $\mathrm{n}^{+} \mathrm{np}^{+}$em lâminas finas de silício monocristalino. In: Actas de la XL Reunión de Trabajo de la Asociación Argentina de Energías Renovables y Medio Ambiente; 2017; San Juan, Argentina. Vol. 5. Buenos Aires: ASADES; 2017. p. 04.13-04.22.

16 Kern W. Handbook of semiconductor wafer cleaning technology. New Jersey: Noyes Publications; 1998.623 p.

17 Zanesco I, Moehlecke A. Desenvolvimento de tecnologias industriais de fabricação de células solares e módulos fotovoltaicos. Rio de Janeiro: FINEP; 2012. Relatório final de Projeto FINEP, convênio FINEP 01.080635.00, ref. $1359 / 08$.

18 Zanesco I, Moehlecke A. Processo de difusão de dopantes em lâminas de silício para a fabricação de células solares. Patente PI12030606, BR 102012030606 9. 2012 Nov 30.

19 Moehlecke A, Zanesco I. Desenvolvimento de células solares eficientes em lâminas de silício tipo n. Rio de Janeiro: FINEP; 2013. Relatório técnico. Projeto FINEP 2102/09.

20 Schroder DT. Semiconductor material and device characterization. 3rd ed. New Jersey: Wiley-Interscience; 2006. $779 \mathrm{p}$.

21 Zhao J, Green M. Optimized antireflection coatings for high-efficiency silicon solar cells. IEEE Transactions on Electron Devices. 1991;38(8):1925-1934.

22 Ly M, Zanesco I, Moehlecke A, Fagundes RS, Cenci AS, Lopes NF, et al. Influência da espessura do filme antirreflexo de $\mathrm{TiO}_{2}$ nos parâmetros elétricos de células solares com base n. In: Anais do IV Congresso Brasileiro de Energia Solar (IV CBENS); V Conferência Latino Americana da ISES; 2012; São Paulo. Recife: ABENS; 2012. p. 1-8.

23 Moehlecke A, Luque A. New approach to obtain boron selective emitters. In: Proceedings of the $1^{\text {st }}$ World Conference on Photovoltaic Energy Conversion; 1994; Havai. New York: IEEE; 1994. p. 1492-1495. http://dx.doi. org/10.1109/WCPEC.1994.520233.

24 Papet P, Nichiporuk O, Kaminski A, Rozier Y, Kraiem J, Lelievre JF, et al. Pyramidal texturing of silicon solar cell with TMAH chemical anisotropic etching. Solar Energy Materials and Solar Cells. 2006;90(15):2319-2328.

25 Krenzinger A, Lorenzo E. Estimation of radiation incident on bifacial albedo-collecting panels. International Journal of Solar Energy. 1986;4(5):297-319. http://dx.doi.org/10.1080/01425918608909865.

Recebido em: 4 Jul. 2019

Aceito em: 6 Out. 2020 